\title{
On the Possibilities of Philosophical Research: Remembering Jaakko Hintikka (1929-2015)
}

Kaarlo Jaakko Juhani Hintikka, born 12 January 1929 in Vantaa, Finland, died on 12 August 2015 in Porvoo, Finland, following a minor accident at his home.

Hintikka's philosophical career and in many ways also his personal life were exceptional. His philosophical journey took a head start when shortly after the war he won a newly established exchange student fellowship, which enabled him to spend a year at Williams College in 1948-1949. From that year spent abroad originates his idea for the semantic completeness proof of first-order logic. After the conferment of the doctoral degree from the University of Helsinki in 1956 (the PhD work was defended in 1953), Hintikka became Junior Fellow of the Society of Fellows at Harvard University (1956-1959). The fellowship was annually awarded to eight scholars to do three years of research without further responsibilities. ${ }^{1}$ Following the Harvard years, Hintikka applied for a professorship at the University of Turku but withdrew his application as soon as he received a position at Helsinki, where he assumed the duties of a Professor of Practical (Moral and Social) Philosophy (1959-1970), followed by the post of research professor at the Academy of Finland (1970-1981). Meanwhile, he was appointed part-time Professor of Philosophy at Stanford University (19651982) and full-time professor at Florida State University (1978-1990). In 1990, he moved to Boston, where he served as full-time Professor of Philosophy at Boston University until his retirement in 2014. He moved back to Finland in 2012 and was Honorary Fellow of the Helsinki Collegium for Advanced Study until his death.

His visiting appointments are equally numerous, including Brown University, University of California Berkeley, and the Hebrew University of Jerusalem. He held the offices of President of the APA Pacific Division, President of the International Union of History and Philosophy of Science, Fellow of the American Academy of Arts and Sciences, Member of the Comité Directeur of Fédération Internationale des Sociétés de Philosophie, Member of the Academy

\footnotetext{
Hintikka mentioned this fellowship to be one of the best things that can happen in one's career: no final reports needed to be submitted, as it was only research that one was expected to do. The fellowship secured him the necessary time and environment to work on the main ideas of Knowledge and Belief, published in 1962.
} 
of Science and Letters of Finland, and Fellow of Societas Scientiarum Fennica. His honors list, too long to be reproduced here, begins in 1952 and includes John Locke and Immanuel Kant Lectures and the 2005 Rolf Schock Prize in Logic and Philosophy. Editor-in-Chief of Synthese for four decades, Hintikka took charge of the office when the editorial was in transition from the Netherlands, first to Finland in the 1970s and then to the U.S. in the 1980s. Until then Synthese had been the official voice for a group of investigators connected to the Significs Circle and to the Unity of Science movement. It is with that transition that the historic term 'significs' that originated from the founders of the journal in 1936 was dropped from its subtitle. Hintikka recounted me the details of those occasions and the journal politics that took place in the early 1960 s. (Publications on significs continued in the hard-to-find journal Methodology and Science until 1995.) No doubt his incessant editorial work with Synthese made Google Scholar an easy task of computing the journal as the leading outlet in philosophy.

Hintikka published 60 books as an author, co-author, editor and co-editor; the exact number of his published articles is uncountable since he usually did not list minor ('non-scientific') writings or editorials in his professional CV and some are still to appear. It is safe to estimate that around 400 scientific papers appeared in journals and collections; unpublished manuscripts, memorandums, published opinion pieces and prefaces offer a rich plenty. Many technical reports, newspaper articles and commentaries are unaccounted for-not everything is online in our day and age. ${ }^{2}$ His last book is not broadly known in the international philosophical community. Published in Finland in 2014 and only in Finnish, Hintikka wrote a biography and a touching personal portrait of his second wife Merrill B. Hintikka, who died in her sleep when only in her late 40s.

Hintikka's research interests are unparalleled in their scope and coverage of the vast terrain of scientific philosophy and its neighbouring disciplines. His scholarly and scientific output reflects his extraordinarily organized pursuit of those interests. He was once introduced as a philosopher who has written on

2 And what is available online is sometimes horrifying, especially in Wikipedia. According to it, Hintikka "devised a semantics of modal logic essentially analogous to Saul Kripke's frame semantics"; that he "did important exegetical work on Aristotle, Kant, Wittgenstein and Peirce"; and that his work is continuous with "the analytic tendency" "advanced by Frege and Russell". Even those with a most superficial and elementary understanding of what his papers contain cannot miss the philosophical reasons why he criticised Kripke, Frege, Russell or Quine, or fail to understand that his interpretations that propose "one-and-the-half-truths" about major thinkers from the past are antagonistic to exegesis. As far as the possible-worlds semantics is concerned, for example, Kripke's proposal arrived after Hintikka and Stig Kanger published their works, or, for that matter, after Peirce's proposal of systems of modal logic in 1903. 
each and every topic in philosophy except medical ethics. In his own words, his research, teaching and supervising activities included the following areas:

- Philosophy of Language and Theoretical Linguistics (game-theoretical semantics, methodology of linguistics, logic and semantics of questions and of question-based dialogues, semantic information and its varieties, the analytic-synthetic distinction, possible-worlds semantics, etc.).

- Foundations of Cognitive Science (interrogative model of inquiry, differences between information processing by humans and computers, knowledge representation and reasoning about knowledge, the psychology of reasoning, mental models, etc.).

- Philosophical Logic (semantics of intensional logics, game-theoretical semantics, independence-friendly logics, non-standard interpretations of logic, problems of individuation and identification, nature of reasoning, urn models, deductive information, etc.).

- Mathematical Logic and Foundations of Mathematics (distributive normal forms, independence-friendly logic, definability, infinitely deep languages, extremality assumptions in mathematical theories, etc.).

- Philosophy of Science (interrogative models of scientific inquiry, the concepts of experiment and induction, why-questions and explanation, inductive logic, decision-theoretical approaches to theory choice, information as utility, identifiability problems in science, theory structure and the different ingredients of an empirical theory, interplay between history of science and philosophy of science, etc.).

- History of Philosophy and History of Ideas (Aristotle, the general assumptions of Greek philosophy, modal concepts in medieval philosophy, Descartes, Leibniz, Kant, the history of the method of analysis, the "principle of plenitude" in the history of philosophy, methodology of the history of ideas, etc.).

- Interpretations of Recent and Contemporary Philosophy (Frege, Peirce, Russell, the Bloomsbury Group, Wittgenstein, Husserl, Carnap, Quine, etc.). ${ }^{3}$

- Philosophy of Education (models of instruction, the role of questions and answers in education, etc.).

- Aesthetics (problems of pictorial representation, philosophy and literature, intentionality and artistic creation, etc.).

3 The "etc.", which many non-Finnish philosophers may not know, include Kepler, Galileo, Spengler and Eino Kaila, plus Hintikka’s little-known papers in political philosophy and philosophy of law only published in Swedish or Finnish. My personal liking is towards his short papers written in the 1950 s and 1960s on history of science and history of ideas. 
The current climate in philosophy has nonetheless turned cold on broad expertise and competence. Departmental practices favour tagging candidates and departments typically seek "complementary research strengths". Now where would Hintikka fit? His intellectual interests led his pursuits. Philosophy was an activity he was compelled to carry out rather than a professional duty call. When the areas of specialization were once required to fit the space under the faculty photos, Jaakko's caption at the department corridor wryly stated: "The history and structure of human thinking". Now what existing research strengths would that complement?

In sober reality, and despite the appearances that the spirit and the letter of his prose might sometimes suggest, Hintikka was a modest and self-deprecating person who recognized well the limitations one inevitably faces during the career that has the rare luck of spanning over sixty years—and which could have been many years longer. His strength was in perceiving what is significant in science and in philosophy. This came from the ability to ask the right questions. When Einstein was asked once how the most important ideas came to him he replied that he was all the time asking the most childish questions.

Hintikka's standard reply to what he takes his most important work to be was: "the next paper". Yet it is worth taking a glance at what the sheer numbers could tell. Citation indices reveal that the top five papers that so far have accrued most citations (in addition to the fifteen books that are in the top 20) are, in this order: 'Impossible Possible Worlds Vindicated' (1979), 'Cogito, Ergo Sum: Inference or Performance?' (1962), 'Quantifiers vs. Quantification Theory' (1974), 'What Is Abduction? The Fundamental Problem of Contemporary Epistemology' (1998), and 'The Semantics of a Certain' (1986). I take this to be a representative list of his work, though no doubt it would also be surprising to many. The problem of logical omniscience, which Hintikka did not take to be a problem as his epistemic notions were intended to model implicit knowledge, and epistemic and modal logics in general, became major methodological approaches in philosophical logic and beyond, although the manners in which intensional logics have been pursued and applied have not quite been what Hintikka wanted them to be. The Descartes/Parmenides paper, inspired by Austin's lectures, shows how shop-worn topics from the history of philosophy could be approached anew, with a hint of courage and lots of linguistic and logical thought: the paper portrays a pathbreaking logical analysis that reveals a self-defeating character of any attempt to think or assert that one does not exist. Branching quantifiers opened up a new direction into which to pursue structures of natural-language quantification and 
of which IF logic is only an inevitable generalization. Abduction and Peirce's logic were close to Hintikka's heart-much closer than Frege or most other household figures in that ill-termed analytical philosophy. "Peirce-miles ahead of Frege in logic and in the philosophy of mathematics", he once told me. A minor surprise is that pretty specific note on the meaning of a certain that nevertheless caught on with the linguists and natural-language semanticists. But yet again, the impact of that paper is explained by the creative insights it has on how a certain structural and logical property is instantiated in informal cognitive and natural-language material. ${ }^{4}$ Finding out such connections and associations between structural relations in logic on the one hand and in language or in thinking on the other was among Hintikka's particular strengths.

What were the next papers that this thinker had on his desk and in his mind? I had a privilege of regularly communicating with him until his untimely death. Together with my father Juhani, whose Doktorvater Hintikka was (Risto Hilpinen and Raimo Tuomela were the other two from Hintikka's first batch of students), we were probably the last ones to extensively discuss some of them with him. The latest of such memorable occasions took place only days and weeks before his death. Atypically for the Nordic, one of the lunches took six hours to be completed. The following is only a fragment of the topics that came up:

- Inconsistencies in the ZFC axiomatic set theory (e.g., that there are false theorems in ZFC—namely, true sentences whose Skolem functions do not exist; axiomatizations lead nowhere; procuring ever more complicated large cardinal axioms is a deadlock);

- The entanglement problem in quantum physics has a logical solution;

- IF logic for vagueness, and we can using IF notions in epistemic logic to construct the first fully viable (i.e. ability to capture presuppositions and conditions on conclusive answers) logic of questions and answers;

- A priori probabilities in Bayes' formula make only partial sense-at some point the continuation of the sequence of evidential facts must be calculated in terms of abductive reasoning.

4 Naturally, the 2006 volume on Hintikka in The Library of Living Philosophers stands out as a singularly remarkable and long-lasting acknowledgment of his accomplishment. Earlier when that volume was contracted for Quine, Jaakko used to refer to the series as "The Library of Almost-Dead Philosophers". The intellectual autobiographies of these volumes testify well on one's character and temperament, philosophical and personal. When Jaakko was in the early 2000s putting final touches on it he confessed that "perhaps the autobiography became a bit too scientific". By scientific he of course meant plenty of forward-looking research proposals, uncertainty of its hypotheses, and perceptive and critical assessment of his own earlier results and achievements. Quine's product was, in sharp contrast, once described by a famous philosopher as "the world's longest postcard". 
- There is a new approach to induction; there is a new interpretation of what mass is in classical physics, as a rotational movement.

This list in the intersections of theoretical, scientific and philosophical questions goes on. To tackle them, we agreed to hold a new research seminar in his town of residence only some weeks and days before his death, as regular commuting to Helsinki was no longer an option.

Hintikka's reluctance to look back on his earlier accomplishments, let alone return to them in anything more than casually and with the sober awareness that they could all be improved upon and continued further, was evident everywhere. When in 2012 I proposed to organize a major conference on epistemic logic, to be entitled Knowledge \& Belief: 50 Years of Logic of the Two Notions, and which would have collected 50 epistemic logicians to Helsinki, it was Hintikka himself who was not impressed. "We want to look fifty years into the future of epistemic logic, not into what was done in the past", he commented. Between the lines one reads a dissatisfaction about the direction epistemic logic had taken over the years, not serving conceptual and philosophical purports in logical and linguistic analysis as he himself had done, but towards computational and philosophically unexciting applications by people whose productions he characterized as "gimmicky but small".

During the last decade or so, Hintikka became very critical towards the situation in contemporary philosophy.

When he decided to return to Finland in 2012 he might have failed to realize that he would not be returning to the same country he had left from, despite the fact that he had regularly visited the place and despite the fact that he had maintained close contact with some of its research communities. Philosophical research had not taken the direction he had hoped for. There were few opportunities for him to continue full-time work or even to find motivated and able students and colleagues to work with and to share and continue the development of his ideas. Today, creative path-breaking attempts are easily labelled "overambitious" and discouraged in the prevailing pseudo-academic milieu. Hintikka felt isolated and suffered from the lack of support, financial and intellectual. Upon his return, the Academy of Finland decided against appointing him as Academy Professor. The very same institution had, in the turmoil of the politically-influenced science politics in the 1970s, decided to turn down his applications and ultimately made him resign from the position of Research Professor. The reason once mentioned to me was that the council did not believe that a man in his early 80 s could carry out the research 
proposed in his research plan. ${ }^{5}$ At one point in 2013 Hintikka even planned to apply for the professorship in theoretical philosophy, the post that became available following the retirement of his former student Ilkka Niiniluoto. ${ }^{6}$

It is not to be doubted that the problems Hintikka wrestled with are extremely difficult. They span a number of areas and disciplines that for mostly historical reasons became compartmentalized and disconnected from each other. When science policy makers and institutional strategies solemnly mention 'interdisciplinarity', do they genuinely mean research projects that actually aim at weaving different areas together in the logical manner Hintikka proposed? A doubt might have crept into pedestrian thought that one person cannot possibly master more than a thin slice of scientific philosophy.

But there are exceptions, albeit not many. Hintikka's research can easily be estimated, by any measure, as the most remarkable Finnish philosophy has ever produced, possibly the most remarkable Finnish science has ever produced. Especially his middle period, from mid-1960s until 1980s was highly successful, when he was running in all measures a true centre of excellence decades before such designations were even invented. At least in philosophy, it is not to be expected that anything comparable to the breadth and depth of his investigations will happen on the Finnish soil again. The reasons for that are of course not anything like personal or intellectual, or concern any one individual; rather they derive from the general observation that the world of science, and that the academic cultures in the relevant institutional structures are no longer the same.

Events and considerations like these tend to confirm the apathy Hintikka identified having broken out not only among contemporary philosophers and philosophical communities but also among research policy makers, panelists,

This was not the only reason, for it is not the only purpose of the Academy of Finland to support high-quality research. The decision-making is organized in such a way that the councils almost automatically begin discriminating against productive applicants who have internationalized their work better than their competitors. There is proof of this, too. The Academy once made a ruling in the early 2000s that went as far as requiring all applicants limit their list of publications to fit one page. This defensive move resulted from the public debate and investigation on applicants' real merits vis-à-vis the funding decisions the Academy had made. Another issue Hintikka did not fail to mention was the age discrimination prevalent in Finland, which is another bias yet to be resolved at both ends of the scale. During the last 12 months we (i.e. I and Juhani) pleaded the Academy of Finland and major Finnish learned societies to urgently support the man whose physical appearance waned but whose mental powers were acute, in order to salvage invaluable thoughts to the posterity. Some of our pleas did not even receive an acknowledgment.

6 Again, his past-retirement age formally prevented that. I for one would have wanted to see the chair-holder satisfy the criterion laid out in the call for that position, namely that "it is an important requirement that the new professor shall further the research lines in which the unit of theoretical philosophy has been traditionally strong and initiate new development". 
experts and reviewers: disbelief that genuine progress can be made on difficult problems that have defied progress for quite some time. Contemporary philosophers and experts have taken the sufficient measure of progress to be that one's work contributes to the ongoing "debates" on relevant matters, how "exegetic" and "scholarly" one's research products are, or how explicitly those interpretations and conclusions are spelled out already at the pre-proposal stage. Hintikka's approach to creative work was in stark contrast fully scientific: his mind focussed on generating hypotheses that may open up avenues for further work. It was not his rationale to make explicit all the conclusions and impacts that may follow, although the latter is so much coveted by policy makers (now including the academic management) with their one-size-fits-all financial instruments and incentives. In multi-disciplinary panels, everyone has his or her own field to guard. But there was never anything proprietary in Hintikka's philosophical and scientific ideas. He often remarked in that good old Peircean spirit that "ideas cannot be owned"- they live their own life anyway.

Hintikka's criticism extended to the very heart of the peer review system, in so far as that system is being abused in today's publication scenes in professional philosophy:

The sad fact is that in our field the referee system has collapsed. (There are undoubtedly some exceptions and your journal hopefully is one of them.) It is bad enough that competent referees are impossible to find in sufficient numbers. The catastrophe is that the referees that major journals rely on do not act responsibly any longer. They do not try to understand the paper they are reading. Instead they are looking for excuse to form a recommendation without having to do any thinking.

Furthermore, those few referees who are using substantial standards normally belong to one of the numerous cliques into which philosophy and philosophical logic has split. The members of one clique do not know and do not care what adherents of the other cult are doing. The standards that a referee is using are those of her or his private club and hence idiosyncratic and ill-educated. The outcome is well calculated to guarantee that no new ideas are published. ${ }^{7}$

The same charge applies not only to the referees but also to the editors, search committee experts and panels whose task supposedly is to provide an objective

\footnotetext{
Hintikka to Jean-Yves Beziau, personal communication on 1 July 2011. Published by permission. Yet in all fairness, Hintikka did not shy away from drawing bold philosophical conclusions from his specific logical investigations.
} 
assessment of the merits of a given scholarly and scientific body of work. I remember one junior editor-in-chief of a reputed philosophy journal once sporting how their policy is to advise referees particularly to look for errors in submissions. But if all you do is to avoid errors in your arguments, you will never become a master of argumentation. A submission that would occasionally slip through the net will be a lifeless, breathless product. It might attest grit and energy but in reality serves merely to contribute to the acceptance rates and impact factors of the very same journal, not to the summum bonum of philosophical acumen. What a masterful way of letting new ideas never to bloom again!

In the formidable task of estimating somebody's significance to the twentiethcentury philosophy and well into the future one can use Hintikka's own analysis of the meaning of "significance": First, there are those philosophers who have greatly contributed to philosophical discussion. They are found occupying top ranks in citation indices and doctoral dissertations are written on their work. As far as their ideas, results and scientific contributions are concerned, they need not be the most significant, however. The research areas their ideas are concerned with may be sheer bubbles full of internal jargon. Second, there are those whose ideas, insights and accomplishments can truly be said to be remarkable and significant, especially in the long run that only time and not your own cult can tell. Thirdly, there are those who can be associated with what being a philosopher apparently means to many: an ideal of the presence of a wise personality, societal involvement and vital cultural resonance.

Is it too early to predict the importance and impact of Hintikka's work to the philosophical sciences of the $20^{\text {th }}$ century and beyond? There are indications suggesting his contributions to arise above so much else that has been recorded in professional philosophy during the second half of the $20^{\text {th }}$ century, at least in the first two of these senses of philosophical significance. Even though he did not care much about bibliometric details, Hintikka's $h$-index is a stellar 64 (at this point the Google Scholar refuses to compute rest of the entries as they exceeded the limit of 1,000). The list is topped by Knowledge \& Belief (1962) with 3,400 citations. Altogether nearly 22,000 citations have been made to his books and papers, a number doubling or tripling those of many philosophical celebrities'. I can only find Mario Bunge, Rom Harré and Daniel D. Dennett who from roughly the same generation of philosophers, and covering roughly similar systematic areas of philosophy, can currently enjoy even more citations 
to their work. ${ }^{8}$ As far as the second sense is concerned, as ever so often in science new and radical ideas may be forgotten for a long time until they are discovered and re-discovered. Hintikka's propositions were never calculated to be safe and neat in the sense that they would provide an easy route to $\mathrm{PhD}$ dissertations or tenure promotions. They demand great navigational skills guided by the grand map of logic. And what that logic is undergoes a revision of its own in that research. As usual, progress in systematic philosophical research just as in science or in organic evolution is not linear; it is highly unpredictable and can move in any direction, forwards and backwards. If his impact to philosophy's future ultimately turns out not to be what he himself wanted to bring about, then also that is what he wanted to bring about.

The greatest tribute one can therefore think of is to further develop, criticize and refute, not precisely what Hintikka has written about on paper but the ideas he has promulgated, and to discover something that one day might be found out to have been due to his mediation in that great continuum of philosophical thought. ${ }^{9}$

Some previously unpublished excerpts from Hintikka's proposals and communications are included in the Appendix. I have selected them in view of providing further support to what was said above.

This result has the obvious limitation of being based on a comparison between existent Google Scholar web pages.

9 The story continues, since Hintikka's philosophical approach and methodology comes surprisingly close to Peirce's pragmaticism, much more than has currently been realized. But this is not solely because of the logical or formal approach: Hintikka's work would be grossly mischaracterized if it were classified as analytical philosophy. Some of the connections between pragmaticism and Hintikka's philosophy can be explained by the similarities in the methods of logic and the significance of logical notations, relational thinking, the value of proofs, and the semantic (model-theoretic, semeiotic) approach both thinkers availed themselves of in philosophical investigation. Once at a philosophy conference I presented details of the connections between Peirce and Jaakko and suggested that the sheer number of them makes one almost believe in reincarnation. To this Jaakko replied: "But who incarnated whom?" 


\section{Appendix ${ }^{10}$}

The first piece below is an extended abstract of a research project that I wrote with my post-Doktorvater in 1999. It was not funded by the Academy of Finland at that time. However, the same proposal was funded in 2002.

\section{IF Logic, Game-Theoretical Semantics, and Their Applications}

Summary. In IF first-order logic, unlike the received first-order logic, one can express all possible patterns of dependence and independence between different variables. This opens up several important possibilities for research. The present project is calculated to explore some of them, including the following: (1) Mutual (e.g. symmetrical) dependencies between quantifiers and their variables can now for the first time be studied by logical methods. The conceptual situation in quantum theory is shown to be a case in point. (2) Other areas opened up include IF second-order logic and the logic of knowledge. (3) IF logic leads to a new understanding of the mechanisms of information flow both in computers and in human information processing. Ways of regulating information flow can in different interesting cases be modelled by means of IF logic or one of its extensions.

Extended abstract. The traditional core area of logic is known as first-order logic alias quantification theory. It turns out, however, that this logic is too weak in its expressive power to do its whole job. Any descriptively adequate logic must clearly be capable of expressing all possible patterns of dependence and independence between variables. In a first-order language, such dependencies between variables are expressed by dependencies between the quantifiers to which they are bound. Accordingly, an adequate quantificational language should be able to represent all possible patterns of dependence and independence between quantifiers. However, the traditional (Frege-Russell) logic does not allow all such patterns and is therefore flawed in an important respect.

This flaw is eliminated in the independence-friendly (IF) logic developed by Hintikka and his associates. This logic is a first-order, and has most of the same 'nice' properties as the received first-order logic, such as compactness, separation theorem, downwards Löwenheim-Skolem theorem, etc. At the same time it possesses a far greater expressive power than ordinary first-order logic. Accordingly, IF first-order logic facilitates new lines of investigation that

\footnotetext{
10 In this appendix, my comments are in italics.
} 
have important consequences for the foundations of mathematics, computer science, cognitive science, philosophy, linguistics and even physics. The present project aims at exploring some such lines of thought. The following are the most prominent ones:

1) Much of the earlier research in IF logic focuses on patterns of quantifiers allowing more independencies than are expressible in Frege-Russell logic. Our aim is to study also patterns of quantifiers that exhibit more dependencies than is allowed by the received Frege-Russell logic, for instance symmetrical dependencies. The logic of such quantifier prefixes has characteristics quite unlike other branches of first-order logic but similar to some of the phenomena in quantum theory. For instance, sets of Skolem functions can be considered as operators. Then the admissible values of 'vectors' of individuals are nothing but eigenvectors of such Skolem operators. Accordingly, one important part of the planned research is an investigation of IF logic as the true quantum logic. Promising exploratory work on this subject is in progress.

2) IF logic, which promises insights into the foundational problems of set theory and the uses of the notion of informational independence in the logic of knowledge (epistemic logic) and in the logic of questions. All these different topics will be investigated by both researchers in cooperation with each other.

3) Recent advances in independence-friendly (IF) logics and game-theoretic semantics (GTS) have also led to a new understanding of the mechanisms of information flow, essential in understanding cognitive activities of humans and computational processes of machines, as well as development of new logical frameworks which can express the flow of information with the aid of games. In a nutshell, information flows between players in a game, and the game is played on a suitable logical language which enables control over the information flow. Ways of regulating the flows amount to different classes of games, whereas a general logical framework of expressing the regulation is provided by IF logics. This approach has significant repercussions in understanding human intelligence in general, and will lead to new perspectives in logic, computer science, cognition, and linguistics.

This project will pursue in two-year period the following detailed aspects of information flow.

i) Investigation of the relations between various ways of regulating the information flow in GTS and IF logics, using logical and game- 
theoretic methods. As games go beyond the ordinary logical methods, new notions of logical equivalence and consequence may emerge.

ii) Widening of the realm of IF logics to epistemic logic, both propositional and first-order. This may result in new notions of bisimulation, relevant in understanding knowledge of players in extensive form of games and important in economics.

iii) As IF logics are new, their consequences abound with applications to semantics of natural language, such as complex nonlinear scope interactions.

iv) Finally, investigating prospects for uniform game-model of cognition and computation aims at a unified perspective on human cognitive activities. This may involve dynamics of interpretation to be applied to games in a novel way.

Further potential applications of IF logics and GTS involve logics of communicating processes and multi-agent architectures in computation.

The following and previously unpublished note from 2000 was written by Hintikka in Finnish. It was circulated among the relevant stakeholders, especially in science policy. It also summarizes his research agenda that he worked on for the last decade and $a$ half.

On the Possibilities of Philosophical Research in Finland. What is it that one must pronounce upon the situation and the future of philosophy in Finland as well as elsewhere in the world? In Finland, philosophy appears to have caught a tail wind. One of the Centres of Excellence focuses on the history of philosophy, and philosophy seems to have been well supported. Professional Finnish philosophers have been active also internationally. There has been a notable interest in philosophy both at the professional and amateur levels. Philosophy is visible also among the wider audience. For instance, the Philosophy Days at Tampere [organized until early 2000] attracted a significant number of spectators. One of our philosophers was elected Rector of the University of Helsinki, and in another context Esa Saarinen has been one of the best known celebrities in the country.

Can we rest content with the situation like this? I recently chatted with a foreign scientist who has visited Finland often and who in general has a very positive outlook on Finnish philosophers. His assessment concerning the true level of the quality of research was, as far as the systematic areas of philosophy 
were concerned, devastatingly critical. ${ }^{11}$ I thought his judgment quite unfair, however-not that it would not have been correct but because similar and also the same criticism can be levelled against most of the philosophical debates taking place elsewhere in the world, too.

Unfair or not, such criticism must be taken seriously. What is it that causes it? To me the easiest way to throw light upon those reasons is to compare the approach contemporary philosophers have towards their work to that of my first philosophical inspiration, Eino Kaila. For Kaila, philosophy literally was a passionate search for the most profound truths in the world and in the human being. This philosophical search for knowledge is in principle no different from the tasks of theoretical special sciences. For Kaila, there was no gap between philosophical and scientific investigation, be that modern physics, biology or psychology.

If under the light of Kaila's example one is to examine the practices of contemporary professional philosophers, one detects a great difference. Symptomatic of it is the attitude contemporary philosophers have towards science. Science and philosophy are not shared enterprises, but "science" is being observed from the vantage point of an outside, often sceptical, observer. Even those philosophers who do welcome science typically do not try to contribute to its progress but, for instance, strive to find among scientific and mathematical results topics for their own philosophical discussion. Organizers of a certain philosophical conference once advertised me their symposium on the philosophy of mathematics whose speakers were supposedly "the leading names in the field". I did not find one sentence in the debates that could have helped a mathematician or a mathematical logician or even made them feel those debates had any relevance to their work. Contemporary philosophers do not ask what they could offer to scientists but what condiment science could offer to them. They do not ask how to study reality but, for instance, "Does science study reality?" It is no better to this situation that the primary reason is not the failure of any individual philosopher but the exhaustion or insufficiency of their research questions and ideas.

It is here that we find a feature that is the most baffling and morbid in the present situation. My personal view is that what is essential in the present situation is in fact very important though it has gone unnoticed. Right now there are promising vistas that are opening up in philosophical research. It is characteristic

${ }_{11}$ Academy of Finland's own summary of the feedback they had received from panels in 2013 confirms these predictions that were made over a decade before. The summary by the Council for Cultural and Social Sciences concludes on applications submitted in philosophy that "despite the fact that the level of application is very high, Finnish philosophical research is currently more interpretative and has the character of commentaries rather than opening up new paths." 
of these ideas that their significance goes beyond the boundaries of philosophy as ordinarily conceived. Their significance justifies exposing them to other scientists and science policy makers, despite the fact that what is at issue is an ongoing and partially preliminary investigation.

The basic structure of all human thinking is logic. It has turned out that the systematization of logic, which for a century now has been thought of as the natural, or basic logic, namely the Frege-Russell logic, is inadequate. It fails to represent all possible combinations of the dependence and independence relations of its variables. To generalize it, so-called IF [independence-friendly] logic was developed, in which all such combinations can be represented. This throws new light on the entire conception of logic, including the relationship between the first-order and higher-order logic.

IF logic has important applications. In the direction of philosophy, it sets one of the basic concepts of our thought, the concept of truth, under a new light, making it possible to explicitly define it. The entire broad-ranging discussion concerning truth thus has to be re-evaluated.

The same new logic has a new role in the foundations of mathematics. Among others, it turns out to be possible in its main role to carry out Hilbert's famous programme in meta-mathematics, which for seventy years has been thought to be impossible. Those different dependence and independence structures of variables IF logic treats also have promising applications to problems of quantum theory. It is already clear that this enables us to understand what is at issue in famous interpretational problems of quantum theory, including the EPR paradox, nonlocality, measurement problem and Schrödinger's cat problem. How this new approach relates to the current formalisms of quantum theory remains to be studied.

It also is apparent that axiomatic set theory, thought to be the natural foundation for the whole of mathematics, is in certain important respects deficient and as a matter of fact erroneous. This calls for the search for a better approach to set-theoretical problems. Since axiomatic set theory is a prevalent frame of reference in mathematical theories, it may be that the practices of mathematical representations have to be revised.

In epistemology, prospects have arisen to treat knowledge-seeking as an interrogative process. The basic idea is the same as in the old Socratic method of questioning. A utilization of this method calls for an adequate logic of 
questions and answers. This logic belongs to what is known as epistemic logic. This logic ("the second-generation epistemic logic") has in its perfectly general form been developed only recently, however. This logic opens up interesting possibilities to investigate human knowledge-seeking activities. Above all, the interrogative model of inquiry makes it possible to apply strategic viewpoints to epistemology.

Those applications are already partially present. It has been recognized that there is a close connection between deductive logic and the logic of discovery inherent in the interrogative model. This result in a way shows that the old thought that even the common sense suggests is right: that all consistent reasoning is "logical" reasoning also outside logic. This thought has sometimes been described as the "Sherlock Holmes logic". It shows how important place logic has in all knowledge seeking.

The point in developing these ideas further is simply to overcome the enchaining limitations that, as I mentioned, hamper contemporary philosophy. For most current epistemologists are exclusively interested in evaluating the status of information already in one's possession, not in how new knowledge is being sought for. Their typical question is when a certain belief of ours deserves to be called knowledge. It turns out, however, that strategies for knowledge justification cannot be evaluated independently of strategies for knowledge acquisition.

In approaching epistemology and scientific reasoning from this point of view, new light is also cast on the role of probability notions in these processes of knowledge acquisition. This role of probability is expected to be reflected in Bayes' formula that expresses how the probability of proposition $\mathrm{H}$ depends on the available evidence E. Reasoning that relies on Bayes' formula has played an important role in the recent theory of statistical and probabilistic reasoning. Its a posteriori probability $\mathrm{P}(\mathrm{H} / \mathrm{E})$ depends however on the prior probabilities of various other propositions, among others. Where do they come from, then? Bayesian theory provides no clear objective answer.

Sometimes a priori probabilities are assumed necessarily to contain subjective elements, and Bayesian theory thus always to rely on a subjective notion of probability.

Some philosophers, first of all Rudolf Carnap, have tried to find purely logical prior probabilities in which to ground our inferences. Investigation has shown, however, that at least under appropriate exemplar situations the optimal choice 
of prior probabilities objectively depends on the facts of the subject matter. It follows that my experience will have to influence rational a posteriori probabilities in ways other than just what the Bayes' formula describes, namely by effecting changes in how a priori probabilities are chosen. No general theory exists for the latter kind of influence, however, despite the enormous significance of the question.

Research on inductive logic provides interesting indications as to how such theory could be developed. These indications are already now obvious enough to cast doubt on certain prevailing conceptions. It is becoming clear, among others, that the theory of cognitive fallacies developed by mathematical psychologists Tversky and Kahneman are fundamentally flawed, despite the fact that their theory has received considerable attention. (Tversky and Kahneman received the pseudo-Nobel Prize in Economics for it.) In this direction the matter at stake is clearly high.

In all these inquiries Finnish philosophers have been and currently are involved in important ways. My review is not to bring forth results that are ready or to accentuate their importance. Most of what has been said is half-baked and many of the interpretations uncertain. According to the usual scientific practice their presentation might even be premature. The reason why I enlist them here is the opportunities they present for the future research. It would be a great disadvantage to miss these opportunities. To have Finnish philosophers participate in developing these new ideas would enable their fruits to be applied, particularly in Finland. It is to be desired that the scientists, especially young scientists, would become aware of the situation and would take these ideas into account in their research plans. To utilize new ideas also requires cooperation between scientists in different fields. In this way we could have philosophical research fruitfully cooperate with other scientific disciplines in the spirit of Eino Kaila.

These perspectives are also to be taken into account in research planning and in decision-making concerning research funding. They deserve special attention also because these opportunities are available not only in philosophy but also in other areas of research that typically belong to different expert panels and research councils beyond ordinary philosophy. 
Next is the outline of Hintikka's 'Peirce and the Future of Logic', an unpublished paper presented at the Second Applying Peirce Conference that I organized at the University of Helsinki on the occasion of Peirce's Centennial in April 22, 2014.

Peirce and the Future of Logic. Peirce's work is relevant to the future of logical theory in several different respects:

1) Peirce represented a model-theoretic (semantical) approach to logic at a time when the idea of logic as calculus was prominent.

2) Peirce's semantics for the logic of quantifiers and connectives was explicitly game-theoretical, anticipating not only contemporary game-theoretical semantics but the mathematical theory of games.

3) In particular, Peirce worked his way to an approach where quantifiers do not merely "range over" a class of values but express through their formal dependencies the actual dependencies of their variables on each other.

4) Peirce was aware that a contrary approach to quantifiers is inadequate.

What precisely are Peirce's ideas and how are they affecting (have affected and will affect) the development of logical theory?

1. Semantical Viewpoint. A semantical viewpoint does not restrict logic to a theory of formal inference. It is necessary in order to see the justification (or lack thereof) for different rules of inference. Peirce was clear about these priorities.

A semantical viewpoint encourages modal logic. Peirce developed various ideas in modal logic which inspired C. I. Lewis but flourished only much later.

Peirce's ideas about the iconic aspects of logic represented a model-theoretical perspective that anticipated model theory proper and different model-oriented developments, e.g., various picture theories.

Peirce's model-theoretical ("iconic") viewpoint made it possible for him to determine how many individuals one is considering at each step of an argument. The number is essentially the quantificational depth of the sentence one is considering. Peirce realized that there is an important difference between two kinds of argument, viz. those in which no new individuals are introduced ("corollarial arguments") and those in which new individuals are needed ("theorematic arguments"). 
He attached a great importance to the distinction: "My first real discovery in logic". The distinction is in fact connected with interesting questions about the length of proofs and about other things in logic including the notorious $\mathrm{P}$ vs. NP problem.

2. Epsilontics. In our days, Frege is usually still presented as the founder of modern logic. Peirce is still neglected to the role of an independent and slightly later co-inventor.

In reality, Frege failed to understand the logic that leading mathematicians were using in his time under the informal guise of "epsilontics" ("Given any $\varepsilon$, one can find a $\delta$ such that...")

- Accordingly, Frege's own logic of quantifiers was seriously flawed, and the same holds for its later forms as the traditional first-order logic.

- In contrast, Peirce understood the epsilon-delta logic perfectly. He did not formalize it, but it would have been easy to incorporate it in his graphical logic.

3. Independence-Friendly Logic. The crucial technical idea is to allow independencies between quantifiers. In the epsilon-delta technique this independence shows up as an independence of different "delta" choices.

So the future of logic depends essentially on whether logicians follow Frege or Peirce. The ideas of latter have been systematized in the so-called independencefriendly (IF) logic.

Hintikka's presentation was then followed by examples of IF sentences such as "There is someone such that if she cannot solve Riemann's Problem, no one can". The logic of this sentence is one in which the conditional (considered as a disjunction with a negation) must be independent of the preceding quantifiers. Such form requires that the individual selected is the same for both disjuncts. This does not happen in ordinary first-order logic. The disjunctive states of affairs are represented in Peirce's logic of existential graphs by what is scribed inside two inner cuts, and ought to be connected by a line of identity, but which nevertheless is ruled out by the ordinary notation that corresponds to traditional first-order logic. Peirce recognized the general form of this problem at various places in his writings published only recently (see Pietarinen, A.-V. (2015), 'Exploring the Beta Quadrant,'Synthese, vol. 192, pp. 941-970). The general diagnosis of the problem situation calls for a generalization of his logic of existential graphs along the lines of IF logic, 
but beginning with the two-dimensional instead of the one-dimensional, linear notation of ordinary logic. ${ }^{12}$

The following outline, entitled 'Logic for Problem Solving' was written in July 2014. It marked an initiation of a collaborative project between us and Chinese scholars to work out a new theory for problem-solving based on the interrogative model of inquiry, which would also then amount to a pedagogically crafted textbook on the tools of logic as a general problem-solving method. The work on that textbook was delayed due to Hintikka's insistence that we should first write a book on the underlying theory of such general methods of reasoning and problem-solving before moving on to the textbook phase.

Logic for Problem Solving. Sherlock Holmes is not the only problem-solver who claims to find his solutions by means of "logic" or by using "deductions". Yet, what this logic and these deductions are has never been spelled out as explicitly and generally as we have come to expect of logical theory. This essay presents an outline of such an explicit logic.

A problem is a kind of question, and solutions to problems are (conclusive) answers to questions. The logic of problems and problem-solving is hence a logic of questions and answers. Excellence in problem-solving consists in asking the right questions and finding answers to them.

This idea is not new. It was fully deliberately practiced clearly by Socrates in his method of questioning or elenchus. This method impressed Plato so much that he made questioning in the form of question games the linchpin of philosophical education in his Academy. When one of his students, called Aristotle, proposed to systematize these games and develop a theory for them, logic and epistemology came about in their Aristotelian incarnation. Later, questioning procedures in the form of obligationes games were an important aspect of the medieval methodology of reasoning. Later, questioning methods were the gist of R. G. Collingwood's approach to thinking and reasoning.

One might be tempted to expect that such a popular methodology should by now have been systematized and analyzed thoroughly. Surprisingly, this is not the case.

12 A mention should also be made of Hintikka's 2009 presentation at the Workshop on Existential Graphs that I organized in Campinas, Brazil. He spoke on "The Significance of Peirce's Existential Graphs": As every ordinary first-order formula can be represented by Peirce's graphs as a disjunction of constituents, they have an especially clear graphical structure. Whether this representability can be extended depends on how dependence and priority scopes are expressed graphically. A successful extension could mean that Peirce's logic is richer than Frege's. The graphs can in any case be seen as a partial answer to the important philosophical question about the model-theoretical meaning of formal logical operations. 
A question is a request of information, and the logic of questions is therefore a part of the logic of information and knowledge. It is easier to develop a logical theory for the notion of information than for philosophers' tricky notion of knowledge.

The logic of questions and answers is sometimes called erotetic logic. There has existed for a while a systematic study of the logic of information (knowledge) called epistemic logic, but its potentialities have not been fully realized. Even the results that have been reached are recent and not very well known among philosophers. The main developments in the theory of questions and answers are the following:

1) In order to define different kinds of knowledge (information) and different kinds of questions, it suffices to have a language (symbolism) in which one can do the following:

i) Express "knowing that $S$ " by an operator $K$, i.e. by $K S$.

ii) Distinguish known (identifiable) objects (i.e. objects of which one can say that one knows who or what they are) from all and sundry existing objects.

iii) Notationally separate from each other objects identified by means of different frameworks, as well as quantifiers ranging over such differently identified objects.

2) A question can be identified by the specification of the epistemic state that the questioner wants to bring about. This specification is called the desideratum of the question.

Desiderata are propositions expressible in the language of epistemic logic, subject to the laws of such logic. They are the main link between epistemic logic and the logic of questions and answers (alias erotetic logic).

3) By means of epistemic logic we can express precisely the question-answer relation, that is, give a criterion as to what response to a question is a conclusive answer (distinguished from a partial answer).

The criterion is a natural one: the response must make (imply) the desideratum.

4) The notion of a presupposition of a question can be made explicit. The presupposition is obtained by omitting all epistemic elements from the desideratum. It asserts the (possibility) existence of a (conclusive) answer.

5) Each new item of information that is introduced into reasoning can be thought of as an answer to a question. This makes it possible to conceptualize every process of knowledge acquisition as a questioning process. ("All inquiry is inquiry"). 
In such a process, a "big" (principal) question is answered by means of a sequence of "small" (operative) questions. A question-answer step in such inquiry is formally a step from the presupposition of a question to a conclusive answer to it, partially analogous to a step from a premises (or set of premises) to a conclusion.

6) An inquiry aiming at a solution of a problem whose desideratum is D, is an attempt to derive $\mathrm{D}$ from the available epistemic premises.

7) The strategic rules and the definitory rules of interrogative inquiry must be distinguished from each other. There is a partial strategic analogy between question-answer steps and deductive steps, but not a definitory one.

This shows one important use of logic in interrogative inquiry.

8) The structure of an interrogative inquiry can be represented by areas of a "logical table" like the tableaux of Evert Beth. Answers to operative questions are added to the "truth" column.

These logical tables capture the structure of the so-called method of analysis and synthesis that has been thought of as an important method of problemsolving and proof-finding.

9) Logical rules of a sequent calculus are obtained by inverting the tableaux rules.

In this way, the meaning of modus ponens, cut rule, etc. can be understood and their relation to the principle of excluded middle can be spelled out. Application of such rules provide presuppositions for yes-no questions.

10) Logical tables can be used to answer "how possible" questions and not only "why necessary" questions.

This expands the applications of logic greatly.

11) Explanations in a strict sense are answers to why-questions. These answers are provided by interpolations in the logical sense. Interpolation formulas result automatically from a suitably regimented logical table.

Pedagogically, the introduction of a student could proceed by stages as follows:

1. Explanation of the interrogative approach. Different kinds of questions and answers.

- Table format. Distinction between interrogative and logical steps.

2. Representation of different arguments in a logical (table) form. (Argument analysis) 
3. Construction of arguments.

- $\quad$ Finding the right questions.

4. Representing table format arguments in ordinary prose. (Composition.)

5. Strategic vs. definitory rules.

- Uncertain answers and how to cope with them.

- Different roles in an interrogative process.

6. Systematization of logical steps

- Logic translation

- Logical notation as a foreign language.

The last communication from Hintikka arrived on the day of his death, sent out to the participants of the CLMPS conference on 12 August 2015.

Dear Colleague,

Scientific congresses are expected to guide the ongoing research in their respective fields. How has our congress done so and where do its results guide us? In order to find out, we are inviting all participants to report their answers. Please tell us the following:

1) Which specific results (yours included) presented at the congress are the most significant ones to the development of our field?

2) Which specific results (yours included) are the most significant ones to the scientists in other fields (mathematics, physics and other physical sciences, biology, psychology and neuroscience, other behavioral sciences, linguistics, etc.)?

3) Which specific problems should researchers in our field(s) tackle next? (What is your brief personal "project description" for the next few years?)

The form of your answer is completely free. But please be specific and realistic. Problems should have unique solutions and there should be a reasonable hope that a solution could be researched in the foreseeable future.

Responses to this survey are sent to the congress address or to hintikka@bu.edu.

Best wishes,

Jaakko Hintikka \& CLMPS 2015 local organizers 
These are essential questions that every philosopher of science would do well to give serious thought on. They signal the worry that philosophy is becoming increasingly disconnected from real scientific work in more than one sense of "disconnected".

My personal acquaintance with Hintikka began with the 1999 CLMPS conference in Krakow and it ended with that conference in Helsinki sixteen years later. In a paper 'Creativity and Conceptions of Man' (published in Finnish in 1984), Jaakko surmises that the source of creative insights could be found in a person — as distinguished from a mere individual - who occupies other possible worlds besides this actual, lowly world of ours. Whether it is in the nature of a creative person that it indeed inhabits worlds that make up the contimuum of all that is, all that ever were, and all that ever will, could and would be - that remains the mystery of all mysteries.

\author{
Ahti-Veikko Pietarinen \\ Professor \& Head of the Chair of Philosophy, \\ Tallinn University of Technology
}

